Journal for ImmunoTherapy of Cancer Robinson PC, Uldrick TS, et al. COVID-19 in immunocompromised populations: implications for prognosis and repurposing of immunotherapies. Journal for ImmunoTherapy of Cancer 2021;9:e002630. doi:10.1136/ jitc-2021-002630

Accepted 27 April 2021

Check for updates

(C) Author(s) (or their employer(s)) 2021. Re-use permitted under CC BY-NC. No commercial re-use. See rights and permissions. Published by BMJ.

For numbered affiliations see end of article.

\section{Correspondence to}

Dr Jason D Goldman;

jason.goldman@swedish.org

\title{
COVID-19 in immunocompromised populations: implications for prognosis and repurposing of immunotherapies
}

\author{
Jason D Goldman (1D , 1,2,3,4 Philip C Robinson (1) , 5,6 Thomas S Uldrick (1) ,3,7 \\ Per Ljungman (D) ${ }^{8,9}$
}

\section{ABSTRACT}

SARS-CoV-2 is the virus responsible for the COVID-19 pandemic. COVID-19 has highly variable disease severity and a bimodal course characterized by acute respiratory viral infection followed by hyperinflammation in a subset of patients with severe disease. This immune dysregulation is characterized by lymphocytopenia, elevated levels of plasma cytokines and proliferative and exhausted T cells, among other dysfunctional cell types. Immunocompromised persons often fare worse in the context of acute respiratory infections, but preliminary data suggest this may not hold true for COVID-19. In this review, we explore the effect of SARS-CoV-2 infection on mortality in four populations with distinct forms of immunocompromise: (1) persons with hematological malignancies (HM) and hematopoietic stem cell transplant (HCT) recipients; (2) solid organ transplant recipients (SOTRs); (3) persons with rheumatological diseases; and (4) persons living with HIV (PLWH). For each population, key immunological defects are described and how these relate to the immune dysregulation in COVID-19. Next, outcomes including mortality after SARS-CoV-2 infection are described for each population, giving comparisons to the general population of age-matched and comorbiditymatched controls. In these four populations, iatrogenic or disease-related immunosuppression is not clearly associated with poor prognosis in HM, HCT, SOTR, rheumatological diseases, or HIV. However, certain individual immunosuppressants or disease states may be associated with harmful or beneficial effects, including harm from severe CD4 lymphocytopenia in PLWH and possible benefit to the calcineurin inhibitor ciclosporin in SOTRs, or tumor necrosis factor- $\alpha$ inhibitors in persons with rheumatic diseases. Lastly, insights gained from clinical and translational studies are explored as to the relevance for repurposing of immunosuppressive hostdirected therapies for the treatment of hyperinflammation in COVID-19 in the general population.

\section{INTRODUCTION}

SARS-CoV-2 is the etiological agent of the disease COVID-19. SARS-CoV-2 was detected in Wuhan, China in December 2019 and rapidly spread around the world creating the most significant global pandemic in a century. As of April 25, 2021, there have been $>146$ million cases diagnosed globally and $>3$ million global deaths. ${ }^{1}$ The course of SARS-CoV-2 infection is variable, with course ranging from asymptomatic, to mild upper respiratory tract infection or non-specific viral illness, to multisystem organ failure and death. ${ }^{2}$ As the course of SARS-CoV-2 infection progresses, disease will resolve in up to $80 \%$ of infected persons, ${ }^{4}$ or will progress to requirement for supplemental oxygen and hospitalization, typically 7-10 days after first onset of symptoms. ${ }^{3}$ In hospitalized persons, the disease is characterized by hypoxia, but other organ system involvement can occur in kidney, heart, liver and brain, with most damage in the non-lung involved organs manifesting as injury related to inflammation. ${ }^{5-9}$ Indeed, the prevailing hypothesis about the pathogenesis of severe disease manifestation implicates immune system dysregulation as opposed to direct viral cytopathic effects. Abnormalities include lymphocytopenia, ${ }^{10} 11$ increased neutrophil-to-lymphocyte ratio, ${ }^{12-14}$ and aberrant cytokine production. ${ }^{15-17}$ The term 'cytokine storm' or 'cytokine release syndrome' has been borrowed from other disease states, specifically chimeric antigen receptor (CAR)-T cell therapy, and engraftment syndrome after allogeneic hematopoietic stem cell transplant, respectively. Cytokine storm is a life-threatening systemic inflammatory syndrome that may involve a variety of innate and adaptive immune cells and that is manifested by elevated levels of circulating cytokines and clinical symptoms due to immune-cell hyperactivation that can lead to multisystem organ dysfunction and/ or death. ${ }^{18}$

Infection with SARS-CoV-2 results in a bimodal disease process. ${ }^{19}$ In the initial phase of illness, typical upper respiratory viral illness or non-specific viral illness symptoms develop including fever, chills, a dry cough, congestion, anosmia, fatigue, myalgia, headache, nausea, and diarrhea. If disease 
does not resolve, there is progression to development of pulmonary phase of illness, with onset of dyspnea and hypoxia with infiltrates of chest radiography ${ }^{20}$ and the need for supportive supplemental oxygen. In hospitalized patients, elevated levels of soluble inflammatory cytokines are present including interleukin (IL)-2, IL-2R, IL-6, IL-7, IL-8, IL-10, granulocyte colony-stimulating factor (G-CSF), and tumor necrosis factor (TNF)- $\alpha{ }^{15-17}$ At this disease stage, activated and exhausted CD8 T cells are associated with increased disease severity. ${ }^{21}{ }^{22}$ Detectable at the severe disease stage are the presence of unusual cell types such as proliferative/exhausted CD4 cells (Ki67, programmed cell death protein 1 (PD-1)) as well as cytotoxic CD4 cells (GNLY). ${ }^{22}$ Other cellular markers of disease progression include loss of functional diversity of CD4 T cells ${ }^{23}$ and increased markers of functional exhaustion measured (ie, PD-1, TIGIT) are associated with worsened antiviral responses and disease progression. ${ }^{24}{ }^{25}$ Plasmablast expansion occurs more in severe disease and B-cell dysregulation may be associated with loss of the regulatory chemokines CXCR5 and CCR6. ${ }^{21}{ }^{22}$ Other dysfunctional cell types such as monocytes and natural killer cells are also associated with COVID-19 disease severity. ${ }^{22}$

Clinical risk factors for more severe COVID-19 disease presentations have been well-described. Age is a significant driver of mortality with an exponential risk as age increases. ${ }^{46}$ Medical comorbidities including diabetes, hypertension, chronic kidney disease, obesity, cancer diagnosis and immunosuppression are also associated with COVID-19 disease progression and death in retrospective studies. ${ }^{27-30}$ Yet the extent to which clinical risk factors such as cancer diagnosis, active treatment or iatrogenic immunosuppression compares with other risk factors such as age or diabetes is not well understood. Respiratory viral infections are often more persistent and severe in immunocompromised persons. ${ }^{31-33}$ However, the risk of immunosuppression on COVID-19 disease outcomes independent from age and comorbidities is incompletely understood. For instance, in the large CCC19 multicenter registry cohort study of patients with cancer infected with SARS-CoV-2, active cancer was associated with a much higher risk for mortality compared with patients with cancer in remission. ${ }^{29}$ The association of higher mortality after SARS-CoV-2 infection in patients with active cancer may be a function of treatment and/or disease-related immunosuppression; or conversely, it may be related to the general higher hazard for death in patients with active cancer. The effects of various immunosuppressive treatments on the progression of SARS-CoV-2 infection may be harmful, have no effect or even be protective.

To address the immune dysregulation caused by SARS-CoV-2, a number of immunosuppressive agents have been repurposed as treatment of COVID-19. This article will explore use of immunosuppressive agents and risk for COVID-19 disease progression in different populations of immunocompromised individuals including solid organ transplant recipients, persons with hematological malignancies (HM), persons with autoimmune conditions on immunosuppression, and PLWH. Here, we review the literature on risk factors of immunosuppressive agents in these populations, compared with other known risk factors, and use of immunosuppressive therapies for treatment of COVID-19 in these populations. Key clinical questions in the management of immunosuppressed persons explored include whether to reduce the use of modifiable iatrogenic immunosuppression in those with COVID-19, or to delay the initiation of otherwise medically indicated immunosuppression or substitute agents in the era of the COVID-19 pandemic. Insights from these populations should be used to initiate randomized controlled trials (RCTs) of immunotherapy drugs repurposed for the treatment of COVID-19.

\section{Hematological malignancies and hematopoietic cell transplant recipients}

Patients with HM and those who have undergone hematopoietic cell transplantation (HCT) have diverse immunosuppressive conditions based on the effect of the underlying malignancy involving the immune system and the immunosuppressive effect of cytotoxic or other therapies, which can affect different compartments of the immune system, with a particular risk from neutropenia. The situation in allogeneic HCT recipients is unique due to the transfer and immune reconstitution from a donor immune system together with prophylaxis and treatment of graft-versus-host disease, typically with agents suppressing T-cell function.

Patients with HM and particularly those who have undergone HCT are prone to develop severe infection with infectious agents including viral infections resulting in significant morbidity and mortality. Therefore, when the COVID-19 pandemic hit, these were patient groups with a perceived increased risk for poor outcome. Reported medical literature describing outcomes in persons with HM or HCT is variable regarding the vulnerability to SARS-CoV-2 infection and disease with some cohorts including all patients with the diagnosis of SARS-CoV-2 infection while others include only hospitalized patients with COVID-19 disease. Wang et al using an US nationwide database for patient electronic medical records showed that patients with HM had an increased risk for COVID-19 infection and that recently diagnosed patients had worse outcome with a $5.1 \%$ death rate overall. ${ }^{34}$ Piñana $e t$ al reported on the Spanish early experience during the COVID-19 pandemic on 367 adult and pediatric patients with HM and showed an overall mortality in non-HCT patients of $31 \%$. Risk factor for death were age $>70$, uncontrolled HM, and neutropenia, although individual HM was not associated with mortality. ${ }^{35}$ In a systematic review and meta-analysis, Vijenthira et al found that adult patients with HM had $34 \%$ risk of death after COVID-19 and that age was the most important factor influencing mortality. ${ }^{36}$

Neutropenia due to COVID-19 is rare in noncancer populations, with lymphocytopenia being the 
predominant hematological derangement. ${ }^{12-14}$ The relationship between baseline neutrophil count and mortality in COVID-19 is U-shaped with increased mortality risk for both neutropenia and neutrophilia. ${ }^{37}$ While neutropenia is a common occurrence in patients with HM, whether depth and duration of neutropenia are associated with outcome in COVID-19 in the HM population is not well studied. Patients with acute leukemia usually have profound and long-lasting neutropenia due to both disease-related and treatment-related factors, so focus on the subpopulation of patients with cancer having leukemia might indirectly describe the role of neutropenia in COVID-19 prognosis. In a registry study with historical controls, Lee et al found that patients with leukemia and COVID-19 had a significantly higher case fatality rate compared with other cancer types, and patients with HM with recent chemotherapy had an increased rate of death during COVID-19-associated hospital admission. ${ }^{38}$ Piñana et al reported that neutropenia $<500$ cells $/ \mu \mathrm{L}$ was associated with an OR for death of 2.8 (95\% CI 1.3 to 6.1), $\mathrm{p}=0.010 .{ }^{35}$ Conversely, in a single-center cohort of hospitalized patients with cancer having COVID-19, Morjaria et $a l$ found neutropenia $<1000$ cells $/ \mu \mathrm{L}$ was not associated with severe respiratory failure or death, and that reversal of neutropenia with G-CSF was associated with increased oxygen need or death. ${ }^{39}$ In a systematic review, no association was noted between any hematological parameter (leukocyte count, platelet count, lymphocyte or neutrophil counts) and mortality in COVID-19 among patients with $\mathrm{HM}^{40}$ In patients with cancer undergoing chemotherapy, COVID-19 disease severity was associated with either high or low lymphocyte counts, low platelet count, or high neutrophil count. ${ }^{41}$ Since neutrophils likely play a role in COVID-19-related pulmonary damage, ${ }^{142}$ reversal of neutropenia in patients with HM with active COVID-19 may not be advisable.

We have some insight about the differential effect of HM and the therapies used to treat HM. García-Suárez reported on a large cohort of hospitalized patients with HM $(n=697)$ in Madrid and showed that age $>60$, acute myeloid leukemia, and active therapy with monoclonal antibodies were significant risk factors for mortality. Conventional chemotherapy showed borderline significance while patients with hypomethylating agents as well as patients with myeloproliferative neoplasms had lower mortality. ${ }^{43}$ In a meta-analysis, Vijenthira et al reported no difference in the risk for death between patients with or without ongoing systemic anticancer therapy. ${ }^{36}$ Case reports suggest patients having received anti-CD20 monoclonal antibody therapy have prolonged viral shedding and that these patients might not develop antibodies to SARS-CoV-2. ${ }^{44}{ }^{45}$ Prolonged viral shedding has also been reported in patients after CAR-T cell therapy, allogeneic HCT, and in a patient with chronic lymphocytic leukemia (CLL), conditions in which B-cell function is suppressed. ${ }^{46}{ }^{47}$ Mato et al showed among 198 patients with CLL with a median age of 70 years an overall case fatality rate at 16 days into the infection of
$33 \%$. There was no difference between treatment-naïve and treated patient including those with Bruton tyrosine kinase inhibitors (BTKi) ${ }^{48}$ Scarfò et al reported mortality $30 \%$ in patients with CLL with a median age of 72 years and found that the risk for severe COVID-19 disease was associated with higher age ( $>65$ years) but neither older age nor comorbidities influenced mortality. ${ }^{49}$ Patients with multiple myeloma showed a similar high mortality as shown by a large series from the International Myeloma Society. Chari et al reported a mortality on 650 hospitalized patients of $33 \%$ with a major geographical variation. Risk factors for poor outcome was higher age, higher stage myeloma, suboptimal myeloma control, and comorbidities. No specific myeloma therapy influenced outcome. $^{50}$

Since patients after HCT have the highest risk for viral disease among patients with $\mathrm{HM}$, the emergence of SARS-CoV-2 and COVID-19 had very strong impact on transplant centers fearing for the outcome of this disease in a population known to be vulnerable to viral infections in general and to community-acquired respiratory viruses. ${ }^{51-56}$ In a report of 318 patients with HCT from the CIBMTR registry, Sharma et alshowed 28-day survival after COVID-19 was $68 \%$. Risk factors for mortality were age $<50$ years, male sex, and development of COVID-19 within 12 months after HCT. ${ }^{57}$ Ljungman et al reported at the 2020 American Society of Hematology meeting on the outcome of 272 patients (175 allogeneic and 97 autologous) diagnosed during the spring of 2020. The median age of this group was 54 years and the overall mortality was $28.6 \%$. Risk factors for mortality was age and poor performance status. ${ }^{58}$ This cohort has now been updated including 382 patients diagnosed during the first wave of COVID-19 in Europe and the attributable mortality to COVID-19 was $25.4 \%$ with risk factors for death being age, performance status, and need for admission to an intensive care unit (ICU) (Ljungman, Leukemia, in press). Shah et al reported similar outcome with a 30-day survival of $78 \%$ on 72 patients with HCT and five CAR-T cell-treated patients. ${ }^{59}$ Piñana $e t$ al reported outcome on 65 allogeneic and 58 autologous HCT recipients of $18 \%$ and $17 \%$, respectively. ${ }^{35}$ Coll et al reported mortality of $20 \%$ and $24 \%$ among 56 patients with allogeneic HCT and 29 patients with autologous HCT, respectively. ${ }^{60}$

Thus, adult patients with HM and after HCT have a substantial mortality in COVID-19, although formal comparisons to the general population are absent. Thankfully, it appears that in pediatric patients with HM and HCT, COVID-19 is less severe. ${ }^{576162}$ It should be recognized that most data exist from the early phases of the pandemic and no series have been presented only including patients diagnosed after the introduction of remdesivir, corticosteroids, and systematic antithromboembolic prophylaxis. It is possible that these interventions can have improved the prognosis in these high-risk groups. 


\section{Solid organ transplant recipients}

Recipients of solid organ transplants (SOTRs) must receive iatrogenic immunosuppression to prevent immunological rejection of the allograft. Antirejection therapy primarily targets T-cell function and is divided into induction and maintenance immunosuppression. Perioperatively, induction is typically achieved via polyclonal antibodies such as rabbit antithymocyte globulin (ATG) combined with high-dose glucocorticoids to achieve immediate allograft tolerance. Maintenance immunosuppression most commonly consists of multimodal regimen to suppress T-cell function including calcineurin inhibitor, with an antimetabolite cell cycle inhibitor, with or without glucocorticoids. Additional high-dose glucocorticoids, anti-T-cell or anti-B-cell therapies, or complement inhibition may be given to treat rejection. The 'net state of immunosuppression' in SOTRs is a complex clinical assessment that details current and past immunosuppression, immunological biomarkers, evidence of infections, or reactivation of latent viral infections. ${ }^{63}$

Antirejection immunosuppression in SOTRs will in general predispose to more severe course of acute infections, including RNA respiratory viral infections including influenza, RSV, and parainfluenza. ${ }^{64}$ Early in the COVID-19 pandemic, small case series detailed high mortality rates on SOTRs, with authors concluding that immunosuppression confers an increased risk of intubation and death for SOTRs. ${ }^{65-67}$ However, mortality in hospitalized SOTRs was not disproportionate to that in the general population in subsequent studies. ${ }^{286869}$ The largest multicenter registry of SOT recipients, Kates et al reported on outcomes in 482 SOTRs. ${ }^{28}$ In the hospitalized subgroup (78\%), 28-day mortality was $20.5 \%$ with older age and comorbidities (especially CHF, chronic lung disease, and obesity) and COVID-19 disease severity at presentation as the main risk factors for mortality. Multiple surrogate measures of immunosuppression intensity were not associated with mortality, including COVID-19 in the early post-transplant course, number of maintenance immunosuppressives, thoracic (lung or heart) transplant, or receipt of recent augmented immunosuppression. ${ }^{28}$ In a multicenter matched cohort, Molnar et al used propensity score matching of 98 SOTRs to 288 non-SOTR persons with critical illness and found similar 28-day morality ( $40 \%$ and $43 \%$, respectively), RR $0.92(95 \%$ CI 0.70 to 1.22$){ }^{68}$ Similarly, in a single-center cohort study, 35 hospitalized SOTRs with COVID-19 were compared with a convenience sample of 100 nontransplant patients with COVID-19 and no difference in mortality was noted ( $23 \%$ vs $25 \%$, respectively), OR $=0.88$ (95\% CI 0.3 to 2.21$).{ }^{69}$ In a study of sequential admissions at two tertiary hospitals in Emilia-Romagna region in Italy, mortality rate in 24 SOTRs was not different from the general population in the multivariate adjusted model for 30-day mortality. ${ }^{70} \mathrm{~A}$ recent systematic review and meta-analysis found an $81.0 \%$ pooled incidence of hospitalization for SOTRs with COVID-19 in 22 studies, likely indicating reporting bias. All-cause mortality after
COVID-19 in SOTRs was 18.6\% in 37 studies reporting, although the timeframe of follow-up was not indicated. ${ }^{71}$

Lung transplant recipients have been significantly affected by the COVID-19 pandemic, an observation which may be due to various factors, which include that the lung and respiratory tract is the site of primary infection of SARS-CoV-2 and also possibly due to use of higher doses of immunosuppression required for this type of transplant, compared with other transplants such as liver and kidney. Case series report mortality ranges from $14 \%$ to $46 \%$. $^{607} 73$ Similarly, heart transplant recipients also require a higher level of immunosuppression and mortality in case series ranges from $25 \%$ to $33 \% .{ }^{74-76} \mathrm{In}$ contrast, most studies of abdominal transplant (kidney and liver transplant) have shown comparable results of SARS-CoV-2 infection in these immunocompromised individuals when compared with the general population. Chavarot et al performed a propensity matched cohort study of kidney transplant recipients from three French centers matched on age and comorbidities to a general hospitalized cohort and found that outcomes including mortality were similar. ${ }^{77}$ The experience in liver transplant recipients also suggested comparable outcomes to the general population. ${ }^{7879}$

The general impact in SOTRs on mortality from COVID-19 due to iatrogenic immunosuppression for antirejection cannot be decisively determined at this time, but together, the data suggest that risks due to immunosuppression are overshadowed by the risks due to age and comorbidities. Evidence-based guidance does not exist for selection of the induction immunosuppressive regimen for SOT programs performing transplant during the pandemic. Review of the US transplant database suggests that SOTRs transplanted during the pandemic were less likely to receive lymphocyte-depleting induction agents. ${ }^{80}$ The vast majority of SOTRs with COVID-19 reported in the medical literature had maintenance immunosuppression reduced or withdrawn. ${ }^{28} 6071$ For example, $70 \%$ of persons in Kates et al had modification to the immunosuppression regimen including antimetabolite withdrawal and reduction in $56 \%$ and $10 \%$, respectively. ${ }^{28}$ In the systematic review and meta-analysis, the antimetabolite was reduced in $76.2 \%$ of SOTRs in 27 studies reporting this observation. ${ }^{71}$ A small single-blind RCT ( $\mathrm{n}=50$; NCT04420364) is assessing strategies for reduction of immunosuppression.

Certain maintenance immunosuppressive agents may have untoward or beneficial consequences, often with conflicting or inconclusive preclinical or clinical data. While the antimetabolite mycophenolic acid (MPA) is effective at strongly inhibiting SARS-CoV-2 in vitro, ${ }^{81}$ MPA is associated in worsening outcome in COVID-19 in a study of liver transplant recipients. ${ }^{78}$ The calcineurin inhibitor, ciclosporin, also inhibits SARS-CoV-2 in vitro, ${ }^{82}$ but has beneficial effects in some clinical studies. ${ }^{83} 84 \mathrm{~A}$ retrospective study assessing a clinical protocol to change tacrolimus to ciclosporin compared with minimization of the tacrolimus dose found a lower proportional mortality 
$12.5 \%$ vs $50 \%$, respectively. ${ }^{85}$ Contradicting this evidence, Belli et al found use of tacrolimus compared with others (ciclosporin, mammalian target of rapamycin inhibitors, or MPA) was associated with a protective effect, HR 0.55 (95\% CI 0.31 to 0.99 ), $\mathrm{p}=0.0470{ }^{86}$ Thus, no firm conclusions on effects from specific maintenance agents can be drawn from these small, uncontrolled, and sometimes conflicting studies.

In summary, the building evidence suggests that SOTRs are not at increased risk of mortality from COVID-19, when compared with age-matched and comorbiditymatched controls, and the effect of immunosuppression on COVID-19 disease progression is uncertain. The vast majority of SOTRs reported in the literature had reduction of immunosuppression, most commonly withdrawal of the antimetabolite component.

\section{Rheumatic diseases}

Patients with rheumatic disease exhibit a broad spectrum of immune dysfunction encompassing inflammatory diseases such as rheumatoid arthritis, connective tissue diseases like systemic lupus erythematosus and systemic vasculitis like giant cell arteritis. These diseases are driven by cell-mediated and antibody-mediated mechanisms with concomitant immunodeficiency also a feature in some diseases. Many of the agents in long-standing agents in use inhibit nucleic acid synthesis like azathioprine and leflunomide, with calcineurin inhibitors also in use targeting T-cell activation. More modern therapeutics target cytokines such as TNF- $\alpha$ or IL-6. B-cell depleting agents are also commonly used in inflammatory arthritis and vasculitis. In patients with rheumatic diseases who acquire SARS-CoV-2 infection, no differences in outcomes have been noted between rheumatic diseases, with differencesdriven age, comorbidities, and specific therapies in use by patients. $^{8788}$

The outcomes of patients with rheumatic diseases during the pandemic have been examined in two different study designs. First, large observational registry studies have been carried out largely by the COVID-19 Global Rheumatology Alliance (GRA). ${ }^{89} 90$ This is an international registry of patients with rheumatic disease from over 40 countries which currently holds $>7000$ cases. The first 110 published cases were largely descriptive and reported a $35 \%$ hospitalization rate and $5 \%$ death rate. ${ }^{91}$ This was followed by a series of 600 patients with the primary outcome being hospitalization for COVID$19 .{ }^{87}$ Factors associated with a higher odds of hospitalization included older age, comorbidities (hypertension/ cardiovascular disease, diabetes, lung disease, renal impairment), and chronic oral glucocorticoid use (prednisone equivalent $\geq 10 \mathrm{mg}$ /day, OR $2.05,95 \%$ CI 1.06 to 3.96). The use of disease-modifying antirheumatic drugs (DMARDs), that is, no anticytokine biological therapies or JAK inhibitors, was associated with a reduced risk of hospitalization (adjusted OR (aOR) 0.46, 95\% CI 0.22 to 0.93), when no DMARD use was used as the referent. This reduced risk of hospitalization was largely driven by TNF inhibitors (anti-TNF), which reduced the odds of hospitalization significantly when used as monotherapy (aOR $0.30,95 \%$ CI 0.11 to 0.79 ).

More recently, the COVID-19 GRA has examined the factors associated with death from COVID-19 in 3729 patients with rheumatic diseases. ${ }^{88}$ Older age, male gender, and certain comorbidities (hypertension, cardiovascular disease, and chronic lung disease) were risk factors for COVID-19-related death. In addition, more rheumatic disease activity compared with low disease activity or remission was also a risk for COVID-19 death (aOR 1.87, 95\% CI 1.27 to 2.77). Medications that increased the odds of death when methotrexate was used as the referent were sulfasalazine (aOR 3.60, 95\% CI 1.66 to 7.78 ), rituximab (aOR 4.04, 95\% CI 2.32 to 7.03 ), and potent immunosuppressants (cyclophosphamide, azathioprine, mycophenolate, ciclosporin, and tacrolimus) assessed as a group (aOR 2.22, 95\% CI 1.43 to 3.46). The group of persons not treated with methotrexate, biological anticytokine DMARDs or JAK inhibitors also had an increased risk of death (aOR 2.11, 95\% CI 1.48 to 3.01). This may be due to unmeasured confounding, but it is worthwhile noting that this group were older and had higher chronic glucocorticoid use. The sulfasalazine association is of interest because on one hand it is generally viewed as less likely to cause infectious complications, but on the other has been identified as interacting with the SARS-CoV-2 spike protein in computational screening studies. ${ }^{92}$ Therefore, the interaction of sulfasalazine with SARS-CoV-2 may be to increase its pathogenicity, or conversely, the group receiving sulfasalazine did not have a beneficial effect of immune-modulating therapy to prevent hyperinflammation of COVID-19. Notably, the two GRA studies used different referents for their medication analyses due to the 'no DMARD' group being an unusual cohort of patients, so the results of these studies would not expect to be directly comparable.

The second study design has been comparative cohort studies. A Boston group published outcomes from the Partners health system early in the pandemic. They matched 52 patients with rheumatic disease and COVID-19 with 104 patients without rheumatic disease and COVID-19. They found no difference in hospitalization or death but did find higher odds of ICU admission and mechanical ventilation. ${ }^{93}$ However, when the same group repeated their study with a larger group of 143 patients and 688 comparators there was not a significantly higher HR for hospitalization, ICU admission, or death. ${ }^{94}$ Neither of these two studies examined the effect of rheumatic medications on COVID-19 outcomes due to lack of power. A much larger comparative cohort study using the US TriNetX network, a large network of health systems with health record data and live updates, included 2379 patients with rheumatic disease and 142750 nonrheumatic disease controls. ${ }^{95}$ Using logistic regression with exposure score matching, and including the covariates age, sex, ethnicity, and body mass index they found small increases in risk for hospitalization, ICU admission, 
acute renal failure, and venous thromboembolism (VTE) in patients with rheumatic disease compared with patients without rheumatic disease, although only the risk for VTE persisted in multivariate regression controlling for comorbidities. No excess risk was found for mechanical ventilation (relative risk (RR) $1.05,95 \%$ CI 0.77 to 1.44 ) or death (RR $1.08,95 \%$ CI 0.81 to 1.44 ). Thus, the risks of poor outcome in patients with rheumatic disease in this group were likely mediated by comorbidities. The use of traditional oral antirheumatic drugs (assessed as a group) or anticytokine biologics and JAK inhibitors (assessed as a group) did not increase the risk of poor outcomes in either of their models. Consistent with the registry studies the use of chronic oral glucocorticoid was a risk for poor outcomes both in their primary model (RR $1.74,95 \%$ CI 1.28 to 2.38 ), and in their extended model which included comorbidities and prior hospitalization (RR $1.50,95 \%$ CI 1.07 to 2.10 ).

The dichotomy between the efficacy of acute glucocorticoids to treat COVID-19 seen in the RECOVERY trial ${ }^{96}$ and poor outcomes seen with chronic glucocorticoid use in patients with rheumatic disease is notable, however the cause of this is currently not entirely clear, ${ }^{97}$ but may be related to timing of use in relation to COVID-19 diagnosis. The findings of improved outcomes in those taking anti-TNF have also been found in other cohorts and in meta-analyses of outcome studies, ${ }^{98-100}$ leading to calls for randomized trials of anti-TNF for the treatment of COVID-19 in the general population. ${ }^{101} 102$ In summary, in patients with rheumatic diseases, major factors increasing the risk of poor outcomes relate to comorbidities, age, and gender, ${ }^{103} 104$ risks shared with the general population. ${ }^{105}$ Risk factors specific to patients with rheumatic disease are also important including chronic glucocorticoid use, rituximab, sulfasalazine, potent immunosuppressants, and elevated disease activity. Other therapies such as anticytokine biologics or JAK inhibitors were not found to be harmful, and especially anti-TNF may have protective effects.

\section{Persons living with HIV}

There are an estimated 1.2 million PLWH in the USA ${ }^{106}$ and $>38$ million people living with HIV globally. Given global scale up of HIV antiretroviral therapy (ART) programs, nearly $70 \%$ of PLWH worldwide are receiving ART. ${ }^{107}$ In the USA, $58 \%$ of prevalent cases are in people $\geq 45$ years of age and $32 \%$ of prevalent cases are in people $\geq 55$ years of age. ${ }^{106}$ Indeed, with decreased AIDS mortality globally with ART, the population of PLWH is aging, with an estimated $20 \%$ of PLWH over the age of 50 globally and $80 \%$ of the PLWH $50+$ population living in lowincome and middle-income countries. ${ }^{108}$ Although life expectancy has increased for PLWH on ART, this population has increased rates of several comorbidities that may affect the severity and natural history of SARS-CoV-2 infection, ${ }^{109}$ including substantially increased risk of cancer, ${ }^{110}$ cardiovascular disease ${ }^{111}$ and non-infectious pulmonary diseases. ${ }^{112}$ Additionally, in the USA, HIV disproportionately affects black and Latino populations, populations also disproportionately affected by COVID19. ${ }^{113}$ Together, these data highlight the importance of considering the burden of COVID-19 in PLWH from a syndemic perspective. ${ }^{114}$

Untreated, HIV leads to CD4 lymphocytopenia in blood and tissues and is associated with chronic inflammation. With combination ART, HIV replication is rapidly controlled, however, immune reconstitution occurs over years, with evidence of T-cell immune dysfunction even 10 years after initiation of ART, especially in people who do not start therapy during acute infection. ${ }^{115} \mathrm{HIV}$ and associated immune dysfunction ${ }^{115}$ has been associated with impaired regulation of oncogenic viruses, with immune control related to CD4 count. ${ }^{110}$ Less is known about the effects of HIV on coronavirus or other respiratory viral infection infections. For influenza, PLWH on ART have similar durations of symptoms and viral shedding and complications compared with HIV-seronegative patients, although among PLWH, viral shedding is increased in those with $<200 \mathrm{CD} 4 \mathrm{~T}$ cells $/ \mathrm{mL} .{ }^{116}{ }^{117}$ Several studies have evaluated COVID-19 outcomes among PLWH (table 1). Population-based studies in the UK ${ }^{118}$ and South Africa ${ }^{119}$ have identified increased COVID-19 mortality among PLWH. COVID-19 case fatality rates among PLWH range from $3.2 \%$ in South Africa to $4.5 \%-20 \%$ in US studies, with differences likely due in part to the age distribution of HIV populations between studies and higher death rates in studies documenting the outcomes in the early COVID-19 pandemic. Results from comparisons of mortality rates between PLWH and HIV-seronegative people diagnosed with COVID-19 have yield variable results. Comorbidities are common in PLWH in all studies, and poor outcomes (eg, ICU level care or death) were associated with comorbidities in PLWH. HIV was not an independent factor for death in most studies that corrected for age and comorbidities associated with death in HIV-seronegative populations.

While HIV infection alone does not appear to be a risk factor for disease progression, people with CD4 $<200 \mathrm{cell} / \mathrm{mL}$ have an estimated $5.22 \quad(95 \%$ CI 1.28 to21.35) increased odds of being hospitalized and 3.32 (95\% CI 1.11 to 9.93) increased odds of worse outcomes with COVID-19. ${ }^{120121}$ CD4 lymphocytopenia is exacerbated by acute SARS-CoV-2 infection, ${ }^{122}$ and increased inflammatory markers (eg, C reactive protein and IL-6) are associated with poor prognosis. ${ }^{123} 124$ It appears that uncontrolled HIV effects T-cell responses during acute SARS CoV2 infection. One study evaluated T-cell dynamics during SARS-CoV-2 infection in 376 PLWH and 382 HIV-seronegative controls. PLWH were grouped by ART use, as 205 had ART suspended during the pandemic due disruptions in supply. This study demonstrated that PLWH on ART and HIV-seronegative patients with COVID-19 had similar augmentation of cytotoxic CD4 and CD8 T-cell responses in blood, while increases were blunted in patients not on ART. Likewise, CD4/CD8 ratio, a measure of immune dysfunction, decreased only 
Table 1 Epidemiological studies of laboratory-confirmed COVID-19 in PLWH

\begin{tabular}{|c|c|c|c|}
\hline Population & Study design & Primary findings & Reference \\
\hline $\begin{aligned} & \text { US HIV-COVID-19 } \\
& \text { Consortium } \\
& 286 \text { cases } \\
& \text { On ART } 93 \% \\
& <200 \text { CD } 4 / m L ~ 15 \%\end{aligned}$ & $\begin{array}{l}\text { Multicenter Registry of PLWH } \\
\text { and COVID-19 }\end{array}$ & $\begin{array}{l}77 \% \text { of cases occurred in those } 40+ \\
\text { years of age. } \\
55 \% \text { required hospitalization based on } \\
\mathrm{O}_{2} \text { saturation }<94 \% \text { or elevated qSOFA } \\
\text { score. } \\
29 \% \text { received ICU level care. } \\
\text { Mortality in PLWH } 9.4 \% \text {. } \\
\text { Hypertension, chronic lung disease } \\
\text { and }<200 \mathrm{CD} 4 / \mathrm{mL} \text { at risk factors } \\
\text { for hospitalization as well as severe } \\
\text { outcomes (ICU or death). }\end{array}$ & Dandachi et al ${ }^{122}$ \\
\hline $\begin{array}{l}\text { Public sector Western } \\
\text { Cape, South Africa } \\
\text { 22,308 COVID-19 cases } \\
18 \% \text { of cases in PLWH } \\
\text { 60\% of PLWH and } \\
\text { COVID-19 with HIV viral } \\
\text { load }<1000 \text { copies/mL }\end{array}$ & Population cohort study & $\begin{array}{l}\text { HIV was associated with standardized } \\
\text { mortality ratio } 2.39 \text { (95\% CI } 1.96 \text { to } 2.86) \text {. } \\
\text { Case fatality in PLWH } 3.2 \% \text {. } \\
\text { Increased death in PLWH and HIV VL } \\
>1000 \text { copies/mL and/or <200 CD4 cells/ } \\
\text { mL. } \\
\text { COVID-19 death associated with current } \\
\text { or prior tuberculosis. }\end{array}$ & Boulle et al ${ }^{119}$ \\
\hline $\begin{array}{l}\text { New York City } \\
\text { Department of Health } \\
204,583 \text { cases COVID-19 } \\
2410 \text { in PLWH } \\
\text { 88\% of PLWH } \\
\text { hospitalized with HIV VL } \\
\text { <200 copies/mL }\end{array}$ & COVID-19 HIV Registry Match & $\begin{array}{l}\text { Compared with all PLWH and all } \\
\text { COVID-19 cases in New York City, } \\
\text { highest proportion in black or Latino and } \\
\text { high-poverty neighborhoods. } \\
\text { Case fatality in PLWH } 12.9 \% \text {. } \\
59 \% \text { of PLWH and COVID-19 had } \geq 1 \\
\text { other comorbidity. } \\
\text { PLWH had higher rates of composite } \\
\text { outcome: hospitalization, ICU admission } \\
\text { and/or death. } \\
\text { Increased ICU admission and death } \\
\text { among PLWH with <200 CD4 cells/mL. } \\
\text { Analyses not-corrected for comorbidities. }\end{array}$ & Braunstein et al ${ }^{121}$ \\
\hline $\begin{array}{l}\text { Mt. Sinai, } \\
\text { Of } 4,402 \text { COVID-19 } \\
\text { admissions, } 88 \text { in PLWH } \\
100 \% \text { on ART }\end{array}$ & $\begin{array}{l}\text { Hospital-based cohort with } \\
5: 1 \text { HIV-seronegative matched } \\
\text { controls }\end{array}$ & $\begin{array}{l}\text { PHLW high increased rates of tobacco } \\
\text { use and COPD. } \\
\text { Case fatality in PLWH } 20 \% \text {. } \\
\text { No increased risk for PLWH after } \\
\text { correcting for comorbidities. }\end{array}$ & Sigel et $a l^{124}$ \\
\hline
\end{tabular}

ICU, intensive care unit; NYC, New York City; PLWH, people living with HIV; qSOFA, quick sepsis-related organ failure assessment; VL, viral load.

in participants not on ART. While immune checkpoint proteins (PD-1 and TIM-1) were increased in all PLWH compared with HIV-seronegative controls, the proportion of cells expressing these immune checkpoints increased during SARS-CoV-2 infection only in PLWH not on ART. These data suggest that ART improves T-cell responses to 
SARS-CoV-2. ${ }^{125}$ Evaluation of plasma cytokines in this same population demonstrated decreased IL-2 and increases in the immunosuppressive factors IL-10 and TGF-b in those not on ART. These data support an important role for ART during SARS-CoV-2 infection. Additional studies are required to evaluate the relative effects of HIV viremia and HIV-associated CD4 lymphocytopenia on adaptive SARS-CoV-2 immune responses in PLWH as well as to evaluate whether there are unique features of cytokine storms in this patient population.

\section{DISCUSSION}

This review summarizes what is known about the effects of immunosuppression on disease progression and mortality in patients from different immunosuppressed populations. SOTRs, patients with rheumatic diseases, and patients with cancer receive iatrogenic immunosuppression as part of their treatment courses, while patients with HM and PLWH have intrinsic disease-related immunosuppression. The weight of evidence at this time does not suggest that all of these types of immunosuppression are associated with increased mortality, especially when the well-known risk factors of age and comorbidities are included in models. ${ }^{126}$ The evidence at this point is based on retrospective studies, many of them registries which are subject to biases and confounding. Based on their mechanism of action, different immunosuppressive medications may be harmful, have no effect, or be beneficial.

Clinical insights from observational data regarding effects of immunomodulatory therapies in the setting of COVID-19 have provided rationale in repurposing of these treatments for the treatment of COVID-19 in the general population. Observational data on use of tocilizumab showed reduced risk for mechanical ventilation or death, ${ }^{127-129}$ which were not realized in subsequent small RCTs. ${ }^{130-132}$ However, newly released trials are now showing promise in reducing combined mechanical ventilation or death, ${ }^{133134}$ or reducing mortality. ${ }^{134} 135$ These latter RCTs also noted a synergistic effect of anti-IL-6 therapy with corticosteroids. ${ }^{134} 135$ Multiple JAK inhibitors have been studied in RCTs for treatment of COVID-19, with baricitinib as the most promising. In the National Institutes of Health (NIH) ACTT-2 trial, remdesivir was used with or without baricitinib, and there was modest additive effect of baricitinib to reduce time to recovery, and trend of decreased mortality with effects seemingly concentrated in the subgroup with baseline need for supplemental oxygen by high flow nasal cannula. ${ }^{136}$ Another large RCT of baricitinib is recently completed (NCT04421027) and top-line results show a promising reduction in mortality. ${ }^{137}$ Early description of COVID-19 outcomes in people with $\mathrm{X}$ linked agammaglobinemia (inherited defect in BTK) and a clinical trial of the BTKi acalabrutinib $^{138}$ supported moving to RCTs, but acalabrutinib failed to meet its primary end point of decreased respiratory failure or death in a phase II trial (NCT04346199). Based on reports of ciclosporin in vitro and observational in vivo benefit, a single-center study from Madrid studied patients with COVID-19 in the general population. In this study, the use of ciclosporin was associated with decrease in mortality, OR 0.24 (95\% CI 0.12 to 0.46$), \mathrm{p}<0.0010$. $^{139}$ A number of small RCTs (NCT04492891, NCT04412785) are studying the repurposed use of ciclosporin for treatment of COVID-19. As noted in rheumatological diseases, anti-TNF therapy had beneficial effects of preventing COVID-19 disease progression when used chronically and primarily for DMARD effect. A small phase II trial has been initiated for the anti-TNF, infliximab, for treatment of COVID-19 (NCT04425538). Lastly, a number of studies have assessed anti-GM-CSF agents including mavrilimumab $^{140141}$ and lenzilumab, ${ }^{142} 143$ with early signals of benefit. The recruiting ACTIV-5 trial will study remdesivir with or without lenzilumab (NCT04583969). Ongoing clinical trials will clarify the role of targeted immunemodulatory drugs. Study design and timing of immunomodulatory administration is likely to be important.

For the treatment of SARS-CoV-2 in persons with immunocompromise, there is no evidence to date suggesting that these immunosuppressed populations should receive different therapy than the general population. Antiviral therapies are important and given longer shedding durations in immunocompromised persons, a longer course of antivirals or initiation later in the disease course may be warranted, although these strategies are unstudied. Baseline immunosuppression may be dose-recued, held, delayed, or replaced with COVID-19-specific therapy such as dexamethasone. The RECOVERY trial ${ }^{96}$ demonstrated that low-dose dexamethasone for up to 10 days decreased mortality in hospitalized patients, with the greatest benefit noted in patients receiving mechanical ventilation. ${ }^{96}$ Thirty-two PLWH were included, although it is unclear if other immunocompromised persons were included. While no subgroup analysis was performed for immunosuppressed persons, the benefit-to-risk profile for dexamethasone use in immunocompromised persons with severe COVID-19 seems favorable. Additional approaches may be appropriate, but should be used with caution. As reviewed above, the results have been mixed for tocilizumab, and these trials in general did not enroll many immunocompromised patients. Other anecdotal evidence exists for tocilizumab use in SOTRs, in addition to antirejection immunosuppression. ${ }^{144} 145$ Tocilizumab has also previously been shown to be safe and have activity in PLWH on ART with Kaposi sarcoma herpesvirus-associated multicentric Castleman disease. ${ }^{146}$ Ideally, patients with immunosuppressed conditions should not be excluded from COVID-19 clinical trials. As described in the section for each immunocompromised population, studies are sparse and controlled trials non-existent to support adjustments to immunosuppression at time of active COVID-19. Thus, recommendations are limited to expert opinion, and society guidelines suggest personalizing the immunosuppression regimen. For transplant recipients (including HCT and SOTRs), the NIH guidelines recommend individualizing changes based on disease 
severity, specific immunosuppressants, transplant type, and risk for graft rejection. ${ }^{147}$ For patients with HM who are candidates for HCT, the American Society for Transplantation and Cellular Therapy recommends to delay HCT procedures in persons with active COVID-19. ${ }^{148}$ For patients with rheumatology, the American College of Rheumatology (ACR) recommends holding immunosuppressant therapies other than IL-6 inhibitors for 2 weeks in the context of active COVID-19. ${ }^{149}$ For PLWH, the NIH guidelines recommend to continue current antiretroviral combination therapy. ${ }^{147}$

A major advance in the prevention of SARS-CoV-2 has been the establishment of effective mRNA vaccines which confer $\sim 95 \%$ protection against COVID-19. ${ }^{150} 151$ These clinical trials mostly excluded immunocompromised persons, but did include PLWH. Additional vaccines are being evaluated. The US Center for Disease Control and Prevention recommend that PLWH and other immunocompromised persons can receive COVID-19 vaccines with proper counseling on lack of safety and efficacy studies and the possibility of reduced immunogenicity. Professional societies including the Society for Immunotherapy in Cancer, American Society of Transplantation and the ACR recommend SARS-CoV-2 vaccine to their patient populations, given the likelihood of expected benefit, despite the lack of published studies. Vaccination is encouraged in these immunosuppressed patient groups, although it is possible that the immune responses will be less robust, as has been seen in response to natural infection. ${ }^{152}{ }^{153}$ Indeed, early studies are showing comparable safety, but reduced immunogenicity has been observed for these populations, including patients with $\mathrm{HM},{ }^{154-156}$ SOTRs, ${ }^{157}$ and those with rheumatological diseases. ${ }^{158} 159$ To achieve comparable vaccine efficacy, further strategies employing altered vaccine schedules, doses, or adjustment to immunosuppression during vaccination might be needed, and should be accomplished only in the context of a clinical trial. More research is needed to assure that SARS-CoV-2 vaccination is safe and effective in immunocompromised persons.

In conclusion, the findings from observational studies of chronically immunosuppressed populations provide fundamental insights into the effects of iatrogenic immunosuppression and whether these therapies could be repurposed for treatment of COVID-19. Anticytokine and other immunomodulatory therapies given for other purposes may have beneficial, harmful, or no effects on COVID-19 disease progression. These therapies are being repurposed from chronic disease-related treatments, to acute therapies in COVID-19 to halt disease progression of aberrant T-cell responses, exhaustion, or cytokine storm. The bimodal disease process of viral and hyperinflammation presents challenges to successful interventional trials which repurpose immunosuppression to prevent hyperinflammation in COVID-19. Careful attention to study design, baseline disease status, and timing of intervention will be needed to draw firm conclusions about where in the COVID-19 disease process immunosuppression is helpful or harmful.

\section{Author affiliations}

${ }^{1}$ Swedish Center for Research and Innovation, Swedish Medical Center, Seattle, Washington, USA

${ }^{2}$ Providence St. Joseph Health, Renton, Washington, USA

${ }^{3}$ Vaccine and Infectious Disease Division, Fred Hutchinson Cancer Research Center, Seattle, Washington, USA

${ }^{4}$ Division of Allergy and Infectious Diseases, Department of Medicine, University of Washington, Seattle, Washington, USA

${ }^{5}$ The University of Queensland Faculty of Medicine, Herston, Queensland, Australia ${ }^{6}$ Metro North Hospital and Health Service, Royal Brisbane and Woman's Hospital Health Service District, Herston, Queensland, Australia

${ }^{7}$ Division of Medical Oncology, Department of Medicine, University of Washington, Seattle, Washington, USA

${ }^{8}$ Department. of Cellular Therapy and Allogeneic Stem Cell Transplantation, Karolinska University Hospital Huddinge, Karolinska Comprehensive Cancer Center, Stockholm, Sweden

${ }^{9}$ Division of Hematology, Department of Medicine, Huddinge, Karolinska Institutet, Stockholm, Sweden

Twitter Philip C Robinson @philipcrobinson and Thomas S Uldrick @ThomasUldrick Contributors All authors contributed to the drafting of the manuscript and approved the final version.

Funding The authors have not declared a specific grant for this research from any funding agency in the public, commercial or not-for-profit sectors.

Competing interests JDG reports research support from Gilead Sciences, Eli Lilly and Regeneron Pharmaceuticals and advisory board and consulting from Gilead and Eli Lilly. PCR reports personal fees from Abbvie, Atom Biosciences, Eli Lilly, Gilead, Janssen, Novartis, UCB, Roche, Pfizer; meeting attendance support from Roche, Pfizer, Lilly and BMS and grant funding from Janssen, UCB and Novartis. TSU receives research support from Celgene/BMS, Merck and Roche and consults for AbbVie and Seattle Genetics. TSU is a co-inventor on US Patent 10 001,483, "Methods for the treatment of Kaposi's sarcoma or KSHV-induced lymphoma using immunomodulatory compounds and uses of biomarkers". PL reports personal fees from Pfizer and Bristol Myers Squibb, about the topic covered in the review; grants and personal fees from MSD, personal fees from AiCuris, Takeda, and Enanta pharmaceuticals, outside the submitted work.

Patient consent for publication Not required.

Provenance and peer review Commissioned; externally peer reviewed.

Open access This is an open access article distributed in accordance with the Creative Commons Attribution Non Commercial (CC BY-NC 4.0) license, which permits others to distribute, remix, adapt, build upon this work non-commercially, and license their derivative works on different terms, provided the original work is properly cited, appropriate credit is given, any changes made indicated, and the use is non-commercial. See http://creativecommons.org/licenses/by-nc/4.0/.

\section{ORCID iDs}

Jason D Goldman http://orcid.org/0000-0002-3825-6832

Philip C Robinson http://orcid.org/0000-0002-3156-3418

Thomas S Uldrick http://orcid.org/0000-0001-6959-0924

Per Ljungman http://orcid.org/0000-0002-8281-3245

\section{REFERENCES}

1 Dong E, Du H, Gardner L. An interactive web-based dashboard to track COVID-19 in real time. Lancet Infect Dis 2020;20:533-4.

2 Gandhi RT, Lynch JB, Del Rio C. Mild or moderate Covid-19. N Engl J Med 2020;383:1757-66.

3 Berlin DA, Gulick RM, Martinez FJ. Severe Covid-19. N Engl J Med 2020;383:2451-60.

$4 \mathrm{Wu}$ Z, McGoogan JM. Characteristics of and important lessons from the coronavirus disease 2019 (COVID-19) outbreak in China: summary of a report of 72314 cases from the Chinese center for disease control and prevention. JAMA 2020.

5 Bradley BT, Maioli $\mathrm{H}$, Johnston R, et al. Histopathology and ultrastructural findings of fatal COVID-19 infections in Washington state: a case series. Lancet 2020;396:320-32. 
6 Hanley B, Naresh KN, Roufosse C, et al. Histopathological findings and viral tropism in UK patients with severe fatal COVID-19: a postmortem study. Lancet Microbe 2020;1:e245-53.

7 Puelles VG, Lütgehetmann M, Lindenmeyer MT, et al. Multiorgan and renal tropism of SARS-CoV-2. N Engl J Med 2020;383:590-2.

8 Bulfamante GP, Perrucci GL, Falleni M, et al. Evidence of SARSCoV-2 transcriptional activity in cardiomyocytes of COVID-19 patients without clinical signs of cardiac involvement. Biomedicines 2020;8. doi:10.3390/biomedicines8120626. [Epub ahead of print: 18 Dec 2020].

9 Matschke J, Lütgehetmann M, Hagel C, et al. Neuropathology of patients with COVID-19 in Germany: a post-mortem case series. Lancet Neurol 2020;19:919-29.

10 Chen N, Zhou M, Dong X, et al. Epidemiological and clinical characteristics of 99 cases of 2019 novel coronavirus pneumonia in Wuhan, China: a descriptive study. Lancet 2020;395:507-13.

11 Huang I, Pranata R. Lymphopenia in severe coronavirus disease-2019 (COVID-19): systematic review and meta-analysis. J Intensive Care 2020;8:36.

12 Liu Y, Du X, Chen J. Neutrophil-To-Lymphocyte ratio as an independent risk factor for mortality in hospitalized patients with COVID-19. J Infect 2020;81:e6-12.

13 Li X, Liu C, Mao Z, et al. Predictive values of neutrophil-tolymphocyte ratio on disease severity and mortality in COVID-19 patients: a systematic review and meta-analysis. Crit Care 2020;24:647.

14 Kuri-Cervantes L, Pampena MB, Meng W, et al. Comprehensive mapping of immune perturbations associated with severe COVID-19. Sci Immunol 2020;5. doi:10.1126/sciimmunol.abd7114. [Epub ahead of print: $15 \mathrm{Jul} 2020]$

15 Huang C, Wang Y, Li X, et al. Clinical features of patients infected with 2019 novel coronavirus in Wuhan, China. Lancet 2020;395:497-506.

16 Del Valle DM, Kim-Schulze S, Huang $\mathrm{H}-\mathrm{H}$, et al. An inflammatory cytokine signature predicts COVID-19 severity and survival. Nat Med 2020;26:1636-43.

17 Qin C, Zhou L, Hu Z, et al. Dysregulation of immune response in patients with coronavirus 2019 (COVID-19) in Wuhan, China. Clin Infect Dis 2020;71:762-8.

18 Fajgenbaum DC, June CH. Cytokine storm. N Engl J Med 2020;383:2255-73

19 Siddiqi HK, Mehra MR. COVID-19 illness in native and immunosuppressed states: a clinical-therapeutic staging proposal. The Journal of Heart and Lung Transplantation 2020;39:405-7.

20 Wong HYF, Lam HYS, Fong AH-T, et al. Frequency and distribution of chest radiographic findings in patients positive for COVID-19. Radiology 2020;296:E72-8.

21 Mathew D, Giles JR, Baxter AE, et al. Deep immune profiling of COVID-19 patients reveals distinct immunotypes with therapeutic implications. Science 2020;369. doi:10.1126/science.abc8511. [Epub ahead of print: 04 Sep 2020].

22 Su Y, Chen D, Yuan D, et al. Multi-Omics resolves a sharp Disease-State shift between mild and moderate COVID-19. Cell 2020;183:e20:1479-95.

23 Zheng $\mathrm{H}-\mathrm{Y}$, Zhang $\mathrm{M}$, Yang $\mathrm{C}-\mathrm{X}$, et al. Elevated exhaustion levels and reduced functional diversity of $\mathrm{T}$ cells in peripheral blood may predict severe progression in COVID-19 patients. Cell Mol Immunol 2020;17:541-3.

24 Diao B, Wang C, Tan Y, et al. Reduction and functional exhaustion of T cells in patients with coronavirus disease 2019 (COVID-19). Front Immunol 2020;11:827.

25 Zheng M, Gao Y, Wang G, et al. Functional exhaustion of antiviral lymphocytes in COVID-19 patients. Cell Mol Immunol 2020;17:533-5.

26 Ho FK, Petermann-Rocha F, Gray SR, et al. Is older age associated with COVID-19 mortality in the absence of other risk factors? general population cohort study of 470,034 participants. PLoS One 2020;15:e0241824.

27 Richardson S, Hirsch JS, Narasimhan M, et al. Presenting characteristics, comorbidities, and outcomes among 5700 patients hospitalized with COVID-19 in the new York City area. JAMA 2020;323:2052

28 Kates OS, Haydel BM, Florman SS, et al. COVID-19 in solid organ transplant: a multi-center cohort study. Clin Infect Dis 2020. doi:10.1093/cid/ciaa1097. [Epub ahead of print: 07 Aug 2020].

29 Kuderer NM, Choueiri TK, Shah DP, et al. Clinical impact of COVID-19 on patients with cancer (CCC19): a cohort study. Lancet 2020;395:1907-18.

30 Lee LY, Cazier J-B, Angelis V, et al. COVID-19 mortality in patients with cancer on chemotherapy or other anticancer treatments: a prospective cohort study. Lancet 2020;395:1919-26.
31 Couch RB, Englund JA, Whimbey E. Respiratory viral infections in immunocompetent and immunocompromised persons. Am J Med 1997;102:2-9

32 Manuel O, Estabrook M, American Society of Transplantation Infectious Diseases Community of Practice. Rna respiratory viral infections in solid organ transplant recipients: guidelines from the American Society of transplantation infectious diseases community of practice. Clin Transplant 2019;33:e13511.

33 Chemaly RF, Shah DP, Boeckh MJ. Management of respiratory viral infections in hematopoietic cell transplant recipients and patients with hematologic malignancies. Clin Infect Dis 2014;59 Suppl 5:S344-51.

34 Wang Q, Berger NA, Xu R. When hematologic malignancies meet COVID-19 in the United States: infections, death and disparities. Blood Rev 2020;100775:100775.

35 Piñana JL, Martino R, García-García I, et al. Risk factors and outcome of COVID-19 in patients with hematological malignancies. Exp Hematol Oncol 2020;9:21.

36 Vijenthira A, Gong IY, Fox TA, et al. Outcomes of patients with hematologic malignancies and COVID-19: a systematic review and meta-analysis of 3377 patients. Blood 2020;136:2881-92.

37 Fu W, Chen C, Chen X-L, et al. A U-shaped association between baseline neutrophil count and COVID-19-related mortality: a retrospective cohort study. J Med Virol 2021. doi:10.1002/ jmv.26794. [Epub ahead of print: 19 Jan 2021].

38 Lee LYW, Cazier J-B, Starkey T, et al. COVID-19 prevalence and mortality in patients with cancer and the effect of primary tumour subtype and patient demographics: a prospective cohort study. Lancet Oncol 2020;21:1309-16.

39 Morjaria S, Zhang A, Kaltsas Md A, et al. The effect of neutropenia and filgrastim (G-CSF) in cancer patients with COVID-19 infection. medRxiv 2020. doi:10.1101/2020.08.13.20174565. [Epub ahead of print: 15 Aug 2020].

$40 \mathrm{Kim}$ JS, Lee KH, Kim GE, et al. Clinical characteristics and mortality of patients with hematologic malignancies and COVID-19: a systematic review. Eur Rev Med Pharmacol Sci 2020;24:11926-33.

41 Grivas P, Khaki AR, Wise-Draper TM, et al. Association of clinical factors and recent anticancer therapy with COVID-19 severity among patients with cancer: a report from the COVID-19 and cancer Consortium. Ann Oncol 2021. doi:10.1016/j. annonc.2021.02.024. [Epub ahead of print: 19 Mar 2021].

42 Dentone C, Vena A, Loconte M, et al. Bronchoalveolar lavage fluid characteristics and outcomes of invasively mechanically ventilated patients with COVID-19 pneumonia in Genoa, Italy. BMC Infect Dis 2021;21:353.

43 García-Suárez J, de la Cruz J, Cedillo Ángel, et al. Impact of hematologic malignancy and type of cancer therapy on COVID-19 severity and mortality: lessons from a large population-based registry study. J Hematol Oncol 2020;13:133.

44 Betrains A, Godinas L, Woei-A-Jin FJSH, et al. Convalescent plasma treatment of persistent severe acute respiratory syndrome coronavirus-2 (SARS-CoV-2) infection in patients with lymphoma with impaired humoral immunity and lack of neutralising antibodies. Br J Haematol 2021;192:1100-5.

45 Kos I, Balensiefer B, Roth S, et al. Prolonged course of COVID-19Associated pneumonia in a B-cell depleted patient after rituximab. Front Oncol 2020;10:1578.

46 Aydillo T, Gonzalez-Reiche AS, Aslam S, et al. Shedding of viable SARS-CoV-2 after immunosuppressive therapy for cancer. N Engl J Med 2020;383:2586-8.

47 Avanzato VA, Matson MJ, Seifert SN, et al. Case study: prolonged infectious SARS-CoV-2 shedding from an asymptomatic immunocompromised individual with cancer. Cell 2020;183:1901-12.

48 Mato AR, Roeker LE, Lamanna N, et al. Outcomes of COVID-19 in patients with CLL: a multicenter international experience. Blood 2020;136:1134-43.

49 Scarfò L, Chatzikonstantinou T, Rigolin GM, et al. COVID-19 severity and mortality in patients with chronic lymphocytic leukemia: a joint study by ERIC, the European Research Initiative on CLL, and CLL Campus. Leukemia : official journal of the. UK: Leukemia Society of America, Leukemia Research Fund, 2020: 34. 2354-63.

50 Chari A, Samur MK, Martinez-Lopez J, et al. Clinical features associated with COVID-19 outcome in multiple myeloma: first results from the International myeloma Society data set. Blood 2020;136:3033-40.

51 Kim Y-J, Guthrie KA, Waghmare A, et al. Respiratory syncytial virus in hematopoietic cell transplant recipients: factors determining progression to lower respiratory tract disease. $J$ Infect Dis 2014;209:1195-204. 
52 Hirsch $\mathrm{HH}$, Martino R, Ward KN, et al. Fourth European conference on infections in leukaemia (ECIL-4): guidelines for diagnosis and treatment of human respiratory syncytial virus, parainfluenza virus, metapneumovirus, rhinovirus, and coronavirus. Clin Infect Dis 2013;56:258-66.

53 Ison MG, Hirsch HH. Community-Acquired respiratory viruses in transplant patients: diversity, impact, unmet clinical needs. Clin Microbiol Rev 2019;32. doi:10.1128/CMR.00042-19. [Epub ahead of print: 18 Sep 2019].

54 Boeckh $\mathrm{M}$. The challenge of respiratory virus infections in hematopoietic cell transplant recipients. Br J Haematol 2008;32:455-67.

55 Zhu W, Wang Y, Xiao K, et al. Establishing and managing a temporary coronavirus disease 2019 specialty hospital in Wuhan, China. Anesthesiology 2020;132:1339-45.

$56 \mathrm{Seo} \mathrm{S}, \mathrm{Xie} \mathrm{H}$, Campbell AP, et al. Parainfluenza virus lower respiratory tract disease after hematopoietic cell transplant: viral detection in the lung predicts outcome. Clin Infect Dis 2014;58:1357-68

57 Sharma A, Bhatt NS, St Martin A, et al. Clinical characteristics and outcomes of COVID-19 in haematopoietic stem-cell transplantation recipients: an observational cohort study. Lancet Haematol 2021;8:e185-93.

58 Ljungman P, De La Camara R, Mikulska M. COVID-19 and stem cell transplantation; results from the prospective survey by the infectious diseases Working Party of the European Society for blood and marrow transplantation (EBMT) and the Spanish hematopoietic stem cell transplantation and cell therapy group (GETH). 62nd annual ash meeting. Available: https://ash.confex.com/ash/2020/ webprogram/Paper138732.html [Accessed 2/21/21].

59 Shah GL, DeWolf S, Lee YJ, et al. Favorable outcomes of COVID-19 in recipients of hematopoietic cell transplantation. $J$ Clin Invest 2020;130:6656-67.

60 Coll E, Fernández-Ruiz M, Sánchez-Álvarez JE, et al. COVID-19 in transplant recipients: the Spanish experience. Am J Transplant 2020. doi:10.1111/ajt.16369. [Epub ahead of print: 23 Oct 2020].

61 Millen GC, Arnold R, Cazier J-B, et al. Severity of COVID-19 in children with cancer: report from the United Kingdom paediatric coronavirus cancer monitoring project. Br J Cancer 2021;124:754759

62 Bisogno G, Provenzi M, Zama D, et al. Clinical characteristics and outcome of severe acute respiratory syndrome coronavirus 2 infection in Italian pediatric oncology patients: a study from the infectious diseases Working group of the Associazione Italiana di Oncologia E Ematologia Pediatrica. J Pediatric Infect Dis Soc 2020;9:530-4.

63 Roberts MB, Fishman JA. Immunosuppressive Agents and Infectious Risk in Transplantation: Managing the "Net State of Immunosuppression". Clin Infect Dis 2020.

64 Manuel O, Estabrook M, ASoTIDCo P, American Society of Transplantation Infectious Diseases Community of Practice. Rna respiratory viral infections in solid organ transplant recipients: guidelines from the American Society of transplantation infectious diseases community of practice. Clin Transplant 2019;33:e13511.

65 Pereira MR, Mohan S, Cohen DJ, et al. COVID-19 in solid organ transplant recipients: initial report from the US epicenter. $A m \mathrm{~J}$ Transplant 2020;20:1800-8.

66 Akalin E, Azzi Y, Bartash R, et al. Covid-19 and kidney transplantation. N Engl J Med 2020;382:2475-7.

67 Fernández-Ruiz M, Andrés A, Loinaz C, et al. COVID-19 in solid organ transplant recipients: a single-center case series from Spain. Am J Transplant 2020;20:1849-58.

68 Molnar MZ, Bhalla A, Azhar A, et al. Outcomes of critically ill solid organ transplant patients with COVID-19 in the United States. Am J Transplant 2020;20:3061-71.

69 Chaudhry ZS, Williams JD, Vahia A, et al. Clinical characteristics and outcomes of COVID-19 in solid organ transplant recipients: a cohort study. Am J Transplant 2020;20:3051-60.

70 Rinaldi M, Bartoletti M, Bussini L, et al. COVID-19 in solid organ transplant recipients: no difference in survival compared to general population. Transpl Infect Dis 2021;23:e13421.

71 Raja MA, Mendoza MA, Villavicencio A, et al. COVID-19 in solid organ transplant recipients: a systematic review and meta-analysis of current literature. Transplant Rev 2021;35:100588.

72 Aversa M, Benvenuto L, Anderson M, et al. COVID-19 in lung transplant recipients: a single center case series from New York City. Am J Transplant 2020;20:3072-80.

73 Messika J, Eloy P, Roux A, et al. COVID-19 in lung transplant recipients. Transplantation 2021;105:177-86.

74 Latif F, Farr MA, Clerkin KJ, et al. Characteristics and outcomes of recipients of heart transplant with coronavirus disease 2019. JAMA
Cardiol 2020. doi:10.1001/jamacardio.2020.2159. [Epub ahead of print: 13 May 2020]

75 Bottio T, Bagozzi L, Fiocco A, et al. COVID-19 in heart transplant recipients: a multicenter analysis of the Northern Italian outbreak. JACC Heart Fail 2021;9:52-61.

76 Rivinius R, Kaya Z, Schramm R, et al. COVID-19 among heart transplant recipients in Germany: a multicenter survey. Clin Res Cardiol 2020;109:1531-9.

77 Chavarot N, Gueguen J, Bonnet G. COVID-19 severity in kidney transplant recipients is similar to nontransplant patients with similar comorbidities. Am J Transplant 2020.

78 Colmenero J, Rodríguez-Perálvarez M, Salcedo M, et al. Epidemiological pattern, incidence, and outcomes of COVID-19 in liver transplant patients. J Hepatol 2021;74:148-55.

79 Webb GJ, Marjot T, Cook JA, et al. Outcomes following SARSCoV-2 infection in liver transplant recipients: an international registry study. Lancet Gastroenterol Hepatol 2020;5:1008-16.

80 Bae S, McAdams-DeMarco MA, Massie AB, et al. Early changes in kidney transplant immunosuppression regimens during the COVID-19 pandemic. Transplantation 2021:105:170-6.

81 Wan W, Zhu S, Li S, et al. High-Throughput screening of an FDA-approved drug library identifies inhibitors against arenaviruses and SARS-CoV-2. ACS Infect Dis 2020. doi:10.1021/ acsinfecdis.0c00486. [Epub ahead of print: 12 Nov 2020].

82 Dittmar M, Lee JS, Whig K. Drug repurposing screens reveal FDA approved drugs active against SARS-Cov-2. bioRxiv 2020;161042.

83 Demir E, Uyar M, Parmaksiz E, et al. COVID-19 in kidney transplant recipients: a multicenter experience in Istanbul. Transpl Infect Dis 2020;22: 13371

84 Rabiee A, Sadowski B, Adeniji N, et al. Liver injury in liver transplant recipients with coronavirus disease 2019 (COVID-19): U.S. multicenter experience. Hepatology 2020;72:1900-1911.

85 Rodriguez-Cubillo B, de la Higuera MAM, Lucena R, et al. Should cyclosporine be useful in renal transplant recipients affected by SARS-CoV-2? Am J Transplant 2020;20:3173-81.

86 Belli LS, Fondevila C, Cortesi PA, et al. Protective role of tacrolimus, deleterious role of age and comorbidities in liver transplant recipients with Covid-19: results from the ELITA/ELTR multi-center European study. Gastroenterology 2021;160:1151-1163.e3.

87 Gianfrancesco M, Hyrich KL, Al-Adely S, et al. Characteristics associated with hospitalisation for COVID-19 in people with rheumatic disease: data from the COVID-19 global rheumatology alliance physician-reported registry. Ann Rheum Dis 2020;79:859-66.

88 Strangfeld A, Schäfer M, Gianfrancesco MA. Factors associated with COVID-19-related death in people with rheumatic diseases: results from the COVID-19 global rheumatology alliance physicianreported registry. Ann Rheum Dis 2021.

89 Wallace ZS, Bhana S, Hausmann JS, et al. The rheumatology community responds to the COVID-19 pandemic: the establishment of the COVID-19 global rheumatology alliance. Rheumatology 2020:59:1204-6.

90 Liew JW, Bhana S, Costello W. The COVID-19 global rheumatology alliance: evaluating the rapid design and implementation of an international registry against best practice. Rheumatology 2020 .

91 Gianfrancesco MA, Hyrich KL, Gossec L, et al. Rheumatic disease and COVID-19: initial data from the COVID-19 global rheumatology alliance provider registries. Lancet Rheumatol 2020;2:e250-3.

92 Wu C, Liu Y, Yang Y, et al. Analysis of therapeutic targets for SARSCoV-2 and discovery of potential drugs by computational methods. Acta Pharm Sin B 2020;10:766-88.

93 D'Silva KM, Serling-Boyd N, Wallwork R, et al. Clinical characteristics and outcomes of patients with coronavirus disease 2019 (COVID-19) and rheumatic disease: a comparative cohort study from a US 'hot spot'. Ann Rheum Dis 2020;79:1156-62.

94 Serling-Boyd N, D'Silva KM, Hsu TY, et al. Coronavirus disease 2019 outcomes among patients with rheumatic diseases 6 months into the pandemic. Ann Rheum Dis 2020. doi:10.1136/ annrheumdis-2020-219279. [Epub ahead of print: 30 Nov 2020].

95 D'Silva KM, Jorge A, Cohen A, et al. COVID-19 outcomes in patients with systemic autoimmune rheumatic diseases (SARDs) compared to the general population: a US multi-center comparative cohort study. Arthritis Rheumatol 2020. doi:10.1002/art.41619. [Epub ahead of print: 10 Dec 2020].

96 Horby P, Lim WS, Emberson JR. Dexamethasone in Hospitalized Patients with Covid-19 - Preliminary Report. N Engl J Med 2020

97 Robinson PC, Morand E. Divergent effects of acute versus chronic glucocorticoids in COVID-19. Lancet Rheumatol 2021;3:e168-70.

98 Akiyama S, Hamdeh S, Micic D. Prevalence and clinical outcomes of COVID-19 in patients with autoimmune diseases: a systematic review and meta-analysis. Ann Rheum Dis 2020. 
99 Winthrop KL, Brunton AE, Beekmann S. Sars CoV-2 infection among patients using immunomodulatory therapies. Ann Rheum Dis 2020.

100 Brenner EJ, Ungaro RC, Gearry RB, et al. Corticosteroids, but not TNF antagonists, are associated with adverse COVID-19 outcomes in patients with inflammatory bowel diseases: results from an international registry. Gastroenterology 2020;159:481-91.

101 Robinson PC, Richards D, Tanner HL, et al. Accumulating evidence suggests anti-TNF therapy needs to be given trial priority in COVID-19 treatment. Lancet Rheumatol 2020;2:e653-5.

102 Robinson PC, Liew DFL, Liew JW, et al. The potential for repurposing anti-TNF as a therapy for the treatment of COVID-19. Med 2020;1:90-102.

103 Gianfrancesco M, Yazdany J, Robinson PC. Epidemiology and outcomes of novel coronavirus 2019 in patients with immune-mediated inflammatory diseases. Curr Opin Rheumatol 2020;32:434-40.

104 Grainger R, Machado PM, Robinson PC. Novel coronavirus disease-2019 (COVID-19) in people with rheumatic disease: epidemiology and outcomes. Best Pract Res Clin Rheumatol 2021;35:101657.

105 Williamson EJ, Walker AJ, Bhaskaran K, et al. Factors associated with COVID-19-related death using OpenSAFELY. Nature 2020;584:430-6.

106 CDC. Estimated HIV incidence and prevalence in the United States, 2014-2018, 2020. Available: https://www.cdc.gov/hiv/pdf/library/ reports/surveillance/cdc-hiv-surveillance-supplemental-report-vol25-1.pdf

107 UNAIDS. Global HIV statistics, 2020. Available: https://www. unaids.org/sites/default/files/media_asset/UNAIDS_FactSheet_en. pdf

108 Autenrieth CS, Beck EJ, Stelzle D, et al. Global and regional trends of people living with HIV aged 50 and over: estimates and projections for 2000-2020. PLoS One 2018;13:e0207005.

109 Harrison SL, Fazio-Eynullayeva E, Lane DA, et al. Comorbidities associated with mortality in 31,461 adults with COVID-19 in the United States: a federated electronic medical record analysis. PLoS Med 2020;17:e1003321

110 Yarchoan R, Uldrick TS. Hiv-Associated cancers and related diseases. N Engl J Med 2018;378:1029-41.

111 Hsue PY, Waters DD. Hiv infection and coronary heart disease: mechanisms and management. Nat Rev Cardiol 2019;16:745-59.

112 Triplette M, Crothers K, Attia EF. Non-Infectious pulmonary diseases and HIV. Curr HIVIAIDS Rep 2016;13:140-8.

113 Bassett MT, Chen JT, Krieger N. Variation in racial/ethnic disparities in COVID-19 mortality by age in the United States: a cross-sectional study. PLoS Med 2020;17:e1003402.

114 Shiau S, Krause KD, Valera P, et al. The burden of COVID-19 in people living with HIV: a Syndemic perspective. AIDS Behav 2020;24:2244-9.

115 Puronen CE, Ford ES, Uldrick TS. Immunotherapy in people with HIV and cancer. Front Immunol 2019;10:10.

116 von Mollendorf C, Hellferscee O, Valley-Omar Z, et al. Influenza vira shedding in a prospective cohort of HIV-infected and uninfected children and adults in 2 provinces of South Africa, 2012-2014. $J$ Infect Dis 2018;218:1228-37.

117 Sheth AN, Althoff KN, Brooks JT. Influenza susceptibility, severity, and shedding in HIV-infected adults: a review of the literature. Clin Infect Dis 2011:52:219-27.

118 Bhaskaran K, Rentsch CT, MacKenna B, et al. Hiv infection and COVID-19 death: a population-based cohort analysis of UK primary care data and linked national death registrations within the OpenSAFELY platform. Lancet HIV 2021;8:e24-32.

119 Boulle A, Davies M-A, Hussey H, et al. Risk factors for coronavirus disease 2019 (COVID-19) death in a population cohort study from the Western Cape Province, South Africa. Clin Infect Dis 2020;7.

120 Vizcarra P, Pérez-Elías MJ, Quereda C, et al. Description of COVID-19 in HIV-infected individuals: a single-centre, prospective cohort. Lancet HIV 2020;7:e554-64.

121 Braunstein SL, Lazar R, Wahnich A, et al. COVID-19 infection among people with HIV in New York City: a population-level analysis of linked surveillance data. Clin Infect Dis 2020. doi:10.2139/ ssrn.3675416. [Epub ahead of print: 30 Nov 2020].

122 Dandachi D, Geiger G, Montgomery MW, et al. Characteristics, comorbidities, and outcomes in a multicenter registry of patients with HIV and coronavirus Disease-19. Clin Infect Dis 2020. doi:10.1093/cid/ciaa1339. [Epub ahead of print: 09 Sep 2020].

$123 \mathrm{HE} \mathrm{H}$, Peluso MJ, Margus C. Clinical outcomes and immunologic characteristics of Covid-19 in people with HIV. J Infect Dis 2020.

124 Sigel K, Swartz T, Golden E, et al. Coronavirus 2019 and people living with human immunodeficiency virus: outcomes for hospitalized patients in New York City. Clin Infect Dis 2020;71:2933-8.

125 Sharov KS. HIV/SARS-CoV-2 co-infection: T cell profile, cytokine dynamics and role of exhausted lymphocytes. Int $J$ Infect Dis 2021;102:163-9.

126 Andersen KM, Mehta HB, Palamuttam N, et al. Association between chronic use of Immunosuppresive drugs and clinical outcomes from coronavirus disease 2019 (COVID-19) hospitalization: a retrospective cohort study in a large US health system. Clin Infect Dis 2021;10.

127 Patel K, Gooley TA, Bailey N, et al. Use of the IL-6R antagonist tocilizumab in hospitalized COVID-19 patients. J Intern Med 2021;289:430-3.

128 Guaraldi G, Meschiari M, Cozzi-Lepri A, et al. Tocilizumab in patients with severe COVID-19: a retrospective cohort study. Lancet Rheumatol 2020;2:e474-84.

129 Han Q, Guo M, Zheng Y, et al. Current evidence of interleukin-6 signaling inhibitors in patients with COVID-19: a systematic review and meta-analysis. Front Pharmacol 2020;11:615972.

130 Stone JH, Frigault MJ, Serling-Boyd NJ, et al. Efficacy of tocilizumab in patients hospitalized with Covid-19. N Engl J Med 2020;383:2333-44.

131 Hermine O, Mariette X, Tharaux P-L, et al. Effect of tocilizumab vs usual care in adults hospitalized with COVID-19 and moderate or severe pneumonia: a randomized clinical trial. JAMA Intern Med 2021:181:32-40.

132 Salvarani C, Dolci G, Massari M, et al. Effect of tocilizumab vs standard care on clinical worsening in patients hospitalized with COVID-19 pneumonia: a randomized clinical trial. JAMA Intern Med 2021:181:24-31.

133 Salama C, Han J, Yau L, et al. Tocilizumab in patients hospitalized with Covid-19 pneumonia. N Engl J Med 2021;384:20-30.

134 Horby PW, Pessoa-Amorim G, Peto L. Tocilizumab in patients admitted to hospital with COVID-19 (recovery): preliminary results of a randomised, controlled, open-label, platform trial. medRxiv $2021 ; 21249258$

135 Gordon AC, Mouncey PR, Al-Beidh F. Interleukin-6 receptor antagonists in critically ill patients with Covid-19 - preliminary report. medRxiv 2021;21249390.

136 Kalil AC, Patterson TF, Mehta AK, et al. Baricitinib plus Remdesivir for hospitalized adults with Covid-19. N Engl J Med 2021;384:795807:795-807.

137 Marconi VC, Ramanan AV, de Bono S, et al. Baricitinib plus standard of care for hospitalized adults with COVID-19. medRxiv: 2021, April 30. https://www.medrxiv.org/content/10.1101/2021.04. $30.21255934 \mathrm{v} 1$

138 Roschewski M, Lionakis MS, Sharman JP, et al. Inhibition of Bruton tyrosine kinase in patients with severe COVID-19. Sci Immunol 2020;5. doi:10.1126/sciimmunol.abd0110. [Epub ahead of print: 05 Jun 2020]

139 Guisado-Vasco P, Valderas-Ortega S, Carralón-González MM, et al. Clinical characteristics and outcomes among hospitalized adults with severe COVID-19 admitted to a tertiary medical center and receiving antiviral, antimalarials, glucocorticoids, or immunomodulation with tocilizumab or cyclosporine: a retrospective observational study (COQUIMA cohort). EClinicalMedicine 2020;28:100591.

140 De Luca G, Cavalli G, Campochiaro C, et al. Gm-Csf blockade with mavrilimumab in severe COVID-19 pneumonia and systemic hyperinflammation: a single-centre, prospective cohort study. Lancet Rheumatol 2020;2:e465-73.

141 Cremer PC, Abbate A, Hudock K, et al. Mavrilimumab in patients with severe COVID-19 pneumonia and systemic hyperinflammation (MASH-COVID): an investigator initiated, multicentre, double-blind, randomised, placebo-controlled trial. Lancet Rheumatol 2021. doi:10.1016/S2665-9913(21)00070-9. [Epub ahead of print: 17 Mar 2021]

142 Temesgen Z, Assi M, Shweta FNU, et al. Gm-Csf neutralization with Lenzilumab in severe COVID-19 pneumonia: a case-cohort study. Mayo Clin Proc 2020;95:2382-94.

143 Humanigen reports positive phase 3 Topline results demonstrating that Lenzilumab ${ }^{\mathrm{TM}}$ improves survival without need for mechanical ventilation in hospitalized patients with COVID-19. Available: https:// ir.humanigen.com/news/news-details/2021/Humanigen-ReportsPositive-Phase-3Topline-Results-Demonstrating-That-LenzilumabImproves-Survival-Without-Need-for-Mechanical-Ventilation-inHospitalized-Patients-With-COVID-19/default.aspx [Accessed $4 / 25 / 21]$

144 Trujillo H, Caravaca-Fontán F, Sevillano Ángel, et al. Tocilizumab use in kidney transplant patients with COVID-19. Clin Transplant 2020;34:e14072 
145 Pereira MR, Aversa MM, Farr MA, et al. Tocilizumab for severe COVID-19 in solid organ transplant recipients: a matched cohort study. Am J Transplant 2020;20:3198-205.

146 Ramaswami R, Lurain K, Peer CJ, et al. Tocilizumab in patients with symptomatic Kaposi sarcoma herpesvirus-associated multicentric Castleman disease. Blood 2020;135:2316-9.

147 COVID-19 treatment guidelines panel. coronavirus disease 2019 (COVID-19) treatment guidelines. National Institutes of health. Available: https://www.covid19treatmentguidelines.nih.gov/ [Accessed 4/25/21].

148 Waghmare A, Abidi MZ, Boeckh M, et al. Guidelines for COVID-19 management in hematopoietic cell transplantation and cellular therapy recipients. Biol Blood Marrow Transplant 2020;26:1983-94.

149 Mikuls TR, Johnson SR, Fraenkel L, et al. American College of rheumatology guidance for the management of rheumatic disease in adult patients during the COVID-19 pandemic: version 3. Arthritis Rheumatol 2021;73:e1-12.

150 Polack FP, Thomas SJ, Kitchin N, et al. Safety and efficacy of the BNT162b2 mRNA Covid-19 vaccine. N Engl J Med 2020;383:2603-15.

151 Baden LR, El Sahly HM, Essink B, et al. Efficacy and safety of the mRNA-1273 SARS-CoV-2 vaccine. N Engl J Med 2021;384:403416:403-16.

152 van Dam P, Huizing M, Roelant E, et al. Immunoglobin G/tota antibody testing for SARS-CoV-2: a prospective cohort study of ambulatory patients and health care workers in two Belgian oncology units comparing three commercial tests. Eur $\mathrm{J}$ Cancer 2021;148:328-39.
153 Thakkar A, Pradhan K, Jindal S, et al. Patterns of seroconversion for SARS-CoV-2 IgG in patients with malignant disease and association with anticancer therapy. Nat Cancer 2021;2:392-9.

154 Agha M, Blake M, Chilleo C, et al. Suboptimal response to COVID-19 mRNA vaccines in hematologic malignancies patients. medRxiv 2021. doi:10.1101/2021.04.06.21254949. [Epub ahead of print: 07 Apr 2021]

155 Monin-Aldama L, Laing AG, Muñoz-Ruiz M. Interim results of the safety and immune-efficacy of 1 versus 2 doses of COVID-19 vaccine BNT162b2 for cancer patients in the context of the UK vaccine priority guidelines. medRxiv 2021.

156 Herishanu Y, Avivi I, Aharon A, et al. Efficacy of the BNT162b2 mRNA COVID-19 vaccine in patients with chronic lymphocytic leukemia. Blood 2021. doi:10.1182/blood.2021011568. [Epub ahead of print: 16 Apr 2021]

157 Boyarsky BJ, Werbel WA, Avery RK, et al. Immunogenicity of a single dose of SARS-CoV-2 messenger RNA vaccine in solid organ transplant recipients. JAMA 2021. doi:10.1001/jama.2021.4385. [Epub ahead of print: 15 Mar 2021].

158 Boyarsky BJ, Ruddy JA, Connolly CM, et al. Antibody response to a single dose of SARS-CoV-2 mRNA vaccine in patients with rheumatic and musculoskeletal diseases. Ann Rheum Dis 2021. doi:10.1136/annrheumdis-2021-220289. [Epub ahead of print: 23 Mar 2021].

159 Deepak P, Kim W, Paley MA, et al. Glucocorticoids and B cell depleting agents substantially impair immunogenicity of mRNA vaccines to SARS-CoV-2. medRxiv 2021. doi:10.1101/2021.04.05.2 1254656. [Epub ahead of print: 09 Apr 2021].

160 Hadi YB, Naqvi SFZ, Kupec JT, et al. Characteristics and outcomes of COVID-19 in patients with HIV: a multicentre research network study. AIDS 2020;34:F3-8. 11. 